\title{
Equipe de saúde mental: análise do discurso sobre a prática no contexto da reforma psiquiátrica
}

\author{
Mental health team: discourse analysis about the practice in the psychiatric reform
}

Equipo de salud mental: análisis del discurso sobre la práctica en la reforma psiquiátrica

Leandro Barbosa de Pinho', Antonio Miguel Bañon Hernández" , Luciane Prado Kantorski"I

'Enfermeiro. Doutor em Enfermagem Psiquiátrica. Professor Adjunto da Faculdade de Enfermagem e Obstetrícia (FEO) da Universidade Federal de Pelotas (UFPEL). Pelotas, RS. E-mail: lbpinho@uol.com.br.

" Professor Titular do Departamento de Filologia da Universidad de Almería (Espanha). Líder do Grupo de Pesquisa Estudios Críticos sobre la Comunicación (ECCO). Almeria, Espanha. E-mail: amhernan@ual.es.

II' Enfermeira. Doutora em Enfermagem. Professora Adjunta da FEO/UFPEL. Pelotas, RS. E-mail: kantorski@uol.com.br.

\section{RESUMO}

A reforma psiquiátrica vem introduzindo, no contexto brasileiro, importantes desafios para pensar a formação das equipes de saúde mental. Este estudo objetiva analisar o discurso de um trabalhador de saúde mental sobre sua própria prática, focalizando aspectos inerentes à formação da equipe para trabalhar nos serviços substitutivos. Procuramos extrair algumas dúvidas, posicionamentos ou ideologias que permeiam a inserção deste trabalhador no contexto atual do cuidado psiquiátrico. Trata-se de uma pesquisa de abordagem qualitativa, desenvolvida no ano de 2006 em um serviço substitutivo de uma cidade do sul do país. O referencial teórico-filosófico utilizado foi a análise crítica do discurso (ACD). Os resultados apontam que o contexto da Reforma Psiquiátrica é capaz de reorientar discursos e processar mudanças, ao mesmo tempo em que encontra barreiras que dificultam sua consolidação. A formação das equipes, por exemplo, já começa a incorporar conhecimentos interdisciplinares, no entanto, na prática ainda concentrada na divisão de habilidades e competências, próximas à multidisciplinaridade. Esperamos que este estudo sirva de subsídio para outros estudos na área, para compreender como, discursivamente, nossa sociedade se relaciona com o louco e a loucura, com as aproximações e os distanciamentos característicos dessa relação.

Descritores: Saúde mental; Ciências sociais; Enfermagem psiquiátrica.

\section{ABSTRACT}

In Brazilian context the Psychiatric Reform is introducing important challenges to think about the mental health team's education. This study aims to analyze the discourse of one mental health worker about the own practice, focusing inherent aspects to the formation of the team for working in the substitutive services. We sought to extract some doubts, positioning or ideologies that permeate the insertion of this worker in the current context of psychiatric care. This is a qualitative research, developed in 2006 at a substitutive service of a city of the southern Brazil. We used the critical discourse analysis (CDA. The results point that the psychiatric reform context is capable to reorient discourses and to process changes, at the same time where it finds barriers that difficult its consolidation. The team's formation starts to incorporate interdisciplinary knowledge, for example. However, in the practical field it is still focused in abilities and competences division, close to the multidisciplinary knowledge. We hope that this study serves as a subsidy for other studies Mental Health to enlarge, discursively, the understanding of how our society relates with the mad and madness, and with the approaches and distancing characteristic of this relationship.

Descriptors: Mental health; Social sciences; Psychiatric nursing.

\section{RESUMEN}

La reforma psiquiátrica ha sido un importante movimiento para discutir, en el contexto brasileño, la formación de los equipos de salud mental. Este estudio pretende analizar el discurso de un trabajador de salud mental sobre su práctica, focalizando aspectos inherentes a la formación del equipo para trabajar en los servicios sustitutivos. Buscamos explotar algunas dudas, posicionamientos o ideologías que permean la inserción del trabajador en el contexto actual del cuidado psiquiátrico. Se trata de una investigación cualitativa, desarrollada en 2006 en un servicio sustitutivo de una ciudad del sur de Brasil. El referencial teórico-filosófico utilizado fue el análisis crítico del discurso (ACD). Los resultados apuntan que el contexto de la Reforma Psiquiátrica es capaz de reorientar discursos y procesar cambios, al mismo tiempo que encuentra barreras que dificultan su consolidación. La formación de los equipos, por ejemplo, ya empieza a incorporar conocimientos interdisciplinarios, sin embargo, en la práctica aún concentrándose en la división de las habilidades y competencias, cercas de la multidisciplinaridad. Esperamos que este estudio sirva de estímulo para otros estudios en el área, para comprender como, discursivamente, nuestra sociedad se relaciona con el loco y la locura, con las aproximaciones y los distanciamientos característicos de esta relación.

Descriptores: Salud mental; Ciencias sociales; Enfermería psiquiátrica. 


\section{NTRODUÇÃO}

Quando perguntamos a alguém o que seria saúde e/ou doença, podemos receber uma multiplicidade de respostas, uma vez que o próprio debate em torno da saúde e da doença sempre foi muito conflituoso. Mesmo assim, saúde e doença são eventos de natureza social, pois nasceram com o desenvolvimento das civilizações. Como tudo na sociedade é complexo, é possível afirmar que saúde e doença também são conceitos e práticas complexos, que silenciosamente repercutem no modo de viver dos sujeitos e na forma de organização coletiva da sociedade.

No campo da saúde, foi a medicina que se desenvolveu mais como profissão do que como saber, destinada a intervir nos fenômenos que alteram as vicissitudes da vida. Com isso, nascem diferentes concepções de saúde e de doença ao longo da história. No entanto, foi com as influências teóricas de René Descartes que a medicina alterou a percepção tradicional do processo de viver humano. Baseado na racionalidade experimental, a medicina funda uma nova rede de saberes e relações dentro da área da saúde, desta vez constituindo um novo conhecimento, de caráter experimentalista e objetivado $^{(1)}$.

Com a conjuntura político-econômica favorável na época, a medicina se desfaz de seus achados empíricos, que buscavam na sintomatologia da doença uma explicação para os fenômenos da vida, incorporando agora saberes experimentais sobre os corpos humanos. O importante agora não era mais identificar os sintomas que levavam a uma enfermidade. Era necessário explorar as causas dela, os porquês dela existir, pois os sintomas não eram mais o fim, mas o meio, o manifestado, o que é previsível. Encontrando as causas, seria possível (e aceitável) compreender os sintomas e tratar os corpos, tanto de indivíduos (a enfermidade particularmente situada) como do coletivo (saúde como projeto político) ${ }^{(2)}$.

No caso específico da saúde mental, foi no mesmo período em que Phillipe Pinel eleva a loucura à categoria de doença mental. Como diretor do Hospital Bicêtre em Paris, em 1793 e depois na Salpetrière, Pinel consegue reorganizar a intervenção à loucura, transformando os asilos franceses em hospitais psiquiátricos (manicômios). A partir desse momento, o saber psiquiátrico se volta para as confluências de um saber racional, que urge pela explicação dos achados do sujeito e de sua manifestação sintomática, assim como pela organização metodológica desses achados para dar início à tecnologia classificatória dos diversos "gêneros" da doença psiquiátrica(3-4).

Como se pôde observar, um discurso não compreende apenas a materialização de determinados pensamentos ou idéias humanas.
Descartes ou Pinel, quando introduziram seus novos conhecimentos na sociedade, também foram responsáveis pela constituição de novas práticas sociais, que pudessem reproduzir suas idéias fundamentais. No caso da saúde, o discurso moderno procurou evitar a divisibilidade, quando a saúde e a doença estavam pulverizadas com concepções contraditórias e sem explicação aparentemente racional. Este discurso foi o grande responsável pela geração de uma nova ordem, de uma nova ideologia, de uma nova compreensão de mundo, de uma nova ação social.

O discurso dominante sobre a doença mental como objeto de intervenção e olhar médico ainda é encontrado na atualidade. No entanto, as críticas que se difundiam no decorrer do século $X X$, em especial no período que sucedeu a Segunda Guerra Mundial, foram fundamentais para redefinir o discurso psiquiátrico sobre a loucura como doença, repensando o papel do manicômio na vida dos sujeitos e os dispositivos de tratamento aplicados por ele. Destacam-se as comunidades terapêuticas inglesas, a psicoterapia institucional francesa, a psiquiatria comunitária americana e a psiquiatria de setor francesa. Esses dois últimos movimentos influenciaram a constituição da Reforma Psiquiátrica Italiana, chamada de democrática, que serviu como modelo fundamental para a constituição de outras reformas no mundo, entre elas a do Brasil ${ }^{(5)}$.

No contexto brasileiro, as Reformas Sanitária e Psiquiátrica foram movimentos incentivadores das discussões sobre a reorganização da assistência psiquiátrica. Caracterizaram-se como movimentos intensos e complexos, de contestação, que contou com a presença de diferentes militantes da sociedade civil. Resultaram da insatisfação com a condução das políticas de saúde no Brasil e com o sentimento de redemocratização que tomou conta do país após a queda do regime ditatorial na década de 70. A Reforma Sanitária buscava transformar a saúde como um "direito" de todos, já que somente os trabalhadores assalariados tinham acesso aos serviços e tratamentos em saúde. A Reforma Psiquiátrica procurou descentralizar as ações do manicômio, considerando que os serviços incluídos na comunidade são mais resolutivos e oferecem tratamentos mais humanizados que aqueles oferecidos nos espaços hospitalares ${ }^{(6-7)}$.

A Reforma Psiquiátrica tem possibilitado constituir novos discursos no campo da saúde mental, revelando faces antes escurecidas pela tradição excludente da psiquiatria tradicional. Hoje, o Centro de Atenção Psicossocial surge como serviço substitutivo ao manicômio e que deve estar articulado, em parceria, com outros serviços de saúde. O louco, nesse sentido, não se constitui um objeto de apreensão, mas como um ser de experiência-sofrimento, participante e que se 
expressa por meio de uma complexidade de manifestações. O tratamento e o cuidado são construídos com base na ideia do tratamento como reflexo e no cuidado como centralidade, sendo o tratamento como projeto e cuidado como condição.

No entanto, a mesma Reforma Psiquiátrica que se preocupa em redimensionar o saber sobre a loucura, ainda enfrenta desafios a superar no contexto brasileiro. No cotidiano dos trabalhadores dos novos serviços, ainda se mesclam diferentes saberes e práticas sobre a loucura. Muitos desses trabalhadores não tiveram a experiência militante para incorporar as transformações na assistência psiquiátrica. Já há estudos ${ }^{(8-9)}$ apontando que determinados processos de trabalho ainda estão focalizados em tecnologias cristalizadas de atendimento, mesmo dentro desses serviços substitutivos, como as relações de poder, a tutelização da loucura, a exclusão das famílias e a culpabilização das mesmas, práticas essas típicas do modelo manicomial.

Nesse sentido, pretendemos analisar o discurso de um trabalhador de saúde mental, focalizando os aspectos inerentes à formação da equipe em saúde mental que trabalha atualmente nos serviços substitutivos.

\section{A TRAJ ETÓRI A METODOLÓGI CA}

Utilizamos, para este estudo, a Análise Crítica de Discurso ( $A C D$ ) como referencial teórico-filosófico para analisar o discurso do trabalhador de saúde mental. Trata-se de uma abordagem teóricometodológica de estudos do discurso que, oriunda das ciências sociais críticas, busca analisar o discurso como produção da sociedade. Sociedade esta que se utiliza da linguagem para veicular poder e ideologia, numa relação muito particular em que se envolvem trocas simbólicas e contradições sociais ${ }^{(10)}$.

O enfoque crítico da análise de discurso nasceu de uma parceria entre as ciências sociais críticas (especialmente aquelas derivadas da Escola de Frankfurt) e as ciências linguísticas. Na tradição crítica da análise de discurso, pode-se citar a influência da Linguística Sistêmico-Funcional, a qual acredita que a linguagem é uma "metáfora" dos processos sociais, assim como uma "expressão" desses processos. A linguística, nesse sentido, teria como função a identificação dessas características por meio da elucidação dos mecanismos internos do texto, onde linguagem, ideologia, prática e interação social se relacionam de forma dialética. No entanto, outros movimentos teórico-filosóficos influenciaram sobremaneira a constituição da Análise Crítica de Discurso como dispositivo de compreensão dos fenômenos discursivos. Destaque para a sociolinguística de Basil Bernstein e para os trabalhos literários de filósofos e cientistas sociais como Michel Pêcheux, Michel Foucault, Jürgen Habermas, Mikhail
Bakhtin e Valentin Voloshinov ${ }^{(10)}$.

Nesse sentido, a Análise Crítica de Discurso adquire uma relevância na análise de determinadas realidades sociais, uma vez que se situa entre a estrutura - as relações existentes no interior do discurso e com outros discursos semelhantes, suas manifestações linguísticas, exigências e funcionamento interno - e a ação propriamente dita - como esse discurso se relaciona com as práticas sociais, constituindo as relações ideológicas e hegemônicas que explicam as contradições, os conflitos, os deslocamentos e os movimentos de determinados fenômenos sociais ${ }^{(11-12)}$.

No contexto da Reforma Psiquiátrica, a análise crítica do discurso pode ajudar a investigar e compreender como se forma e se difunde o discurso do trabalhador em saúde mental. Ela pode revelar aproximações e distanciamentos no que se refere ao atendimento do usuário, de sua família e à formação e consolidação da rede de serviços ${ }^{(13)}$. Mais do que isso, entendemos que a análise crítica de discurso pode contribuir para entender os diferentes mecanismos que são inerentes a esse discurso, as ideologias e hegemonias que o compõem, assim como as repercussões destas no cotidiano da prática em saúde mental (a formação da equipe, as práticas conflituosas ou complementares, as rupturas com modelos tradicionais em saúde mental ou, até mesmo, a assimilação desses modelos no contexto atual das práticas).

A partir de uma entrevista aplicada a um profissional de saúde mental de um serviço substitutivo, exemplificamos alguns procedimentos metodológicos de análise crítica de discurso, no que tange à constituição da equipe de saúde mental. A seguir, apresentamos esses procedimentos e a análise propriamente dita.

O corpus deste trabalho é composto por uma entrevista, aplicada a um profissional de saúde mental, no ano de 2006, que trabalhava em um serviço substitutivo de uma cidade do Sul do Brasil. Foram realizadas duas perguntas-chave, das quais: "Fale-me um pouco sobre o atendimento do serviço" e "fale-me um pouco sobre os fatores que podem contribuir para o melhor funcionamento do serviço".

A entrevista teve caráter não-diretivo, no intuito de deixar o entrevistado livre para fazer comentários e sugestões. Foi gravada em uma fita cassete e, depois de concluída, encaminhada a dois digitadores diferentes, responsáveis pela transliteração da gravação.

Nos estudos do discurso, a transcrição concentra-se na descrição detalhada de todos os fenômenos semióticos envolvidos nas conversações, como: pausas, entonações, corte de sílabas ou sinais verbais/não verbais. No caso da transliteração, compreende-se a transcrição dos signos lingüísticos, mas utilizando-se uma ortografia convencional para 
descrever apenas os enunciados produzidos pelos falantes, sendo o nível mais comum de representação de todos os corpus orais ${ }^{(14)}$.

A entrevista totalizou quatro laudas e foi lida na íntegra para uma primeira sensibilização. Nesta primeira etapa, procuramos analisar o fluxo do raciocínio lógico do trabalhador e algumas questões de conteúdo, dando ênfase àquelas que estão relacionadas à constituição da equipe de saúde mental. Como não é possível reproduzir a entrevista em sua totalidade, em função do espaço limitado para esta produção, selecionamos alguns fragmentos da entrevista que pudessem subsidiar essas discussões.

Diferentemente dos procedimentos analíticos tradicionais nas análises qualitativas, a análise de discurso - resguardando as diferentes vertentes existentes e suas especificidades - procura identificar as estruturas linguísticas que dão sentido às experiências relatadas e constituídas no discurso. Em análise de conteúdo, por exemplo, o foco da análise é a extração do conteúdo significante a partir de uma manifestação linguística (o texto). Já em análise de discurso, é mais interessante investigar aquilo que produz o conteúdo, as implicações inerentes a isso e como esse conteúdo produz essas implicações (as estruturas do discurso). É isso que, para a análise de discurso, dará significado à prática e um sentido singular à realidade social.

O projeto foi submetido previamente a avaliação pelo Comitê de Ética em Pesquisa da Faculdade de Medicina da Universidade Federal e Pelotas (UFPEL), obtendo parecer favorável ao seu desenvolvimento (Ofício 074/2005). Foi, também, garantido o anonimato dos sujeitos do estudo e respeitados todos os preceitos ético-legais que regem a pesquisa com seres humanos, como é preconizado pelo Ministério da Saúde (Resolução 196/96 do Conselho Nacional de Saúde).

\section{RESULTADOS E DISCUSSÃO}

\section{Perfil geral do trabalhador entrevistado e do discurso produzido}

O trabalhador entrevistado é assistente social. Trabalha no serviço desde sua implantação, e, na área da saúde mental, desde 1995. Comentou que o início de suas atividades profissionais na área foi marcado pelo despreparo, já que não possuía experiência prévia na área. No entanto, afirmou que isso não a inviabilizou de perguntar, questionar, tirar dúvidas com outros profissionais e participar de grupos ou oficinas, pois era uma maneira também de se aproximar deles. Com isso, foi aprendendo um pouco como operar no campo da saúde mental, tanto com as questões mais específicas dos usuários, quanto com a integração com o serviço e com a proposta.
Para ele, é importante que uma atividade terapêutica não seja centralizada no diagnóstico, mas na visão do ser por inteiro. Para isso, cada profissional deve desenvolver consciência de que o usuário tem limitações e potencialidades, ambas a serem trabalhadas num projeto terapêutico.

O trabalhador seguidamente fez referências ao fato de que gosta da área da saúde mental, identifica-se muito com ela e que cresceu muito trabalhando no serviço. Relatou que não é fácil trabalhar nesse campo, que muitas vezes é desgastante e que até causa desmotivação com alguns conflitos que nascem do cotidiano do processo de trabalho. Mesmo assim, diz que gosta de estar com o usuário, que está sempre aberto às sugestões, que são importantes num contexto tão dinâmico como é a saúde mental, e que trabalhar com isso é uma satisfação, não uma obrigação. Por considerar o seu trabalho assim, informou que sempre buscou conhecer outras atividades que não fazem parte de sua formação específica, como a medicação (efeitos, contra-indicações e indicações). Até porque, para esse trabalhador, um profissional de um serviço de saúde mental precisa conhecer um pouco de tudo, ter um conhecimento geral para poder lidar com as diferentes demandas que aparecem do usuário (que também é único).

A partir de uma primeira sensibilização, o discurso do entrevistado procura focalizar-se em dois aspectos fundamentais: o funcionamento do serviço e a organização das práticas da equipe de trabalhadores. Percebemos também que há uma oscilação entre uma perspectiva de entusiasmo com a proposta do serviço (original, nova, diferenciada do manicômio), ao mesmo tempo em que se depara com a desmotivação criada com os problemas cotidianos no ambiente de trabalho (rotatividade de profissionais, contratos temporários, conflitos interpessoais e o modo mutante de operar na área que gera imprecisão e incerteza).

Outra situação interessante é a de que, ao avaliar superficialmente o conteúdo do discurso, existe uma tentativa de valorizar o serviço atual, quando comparado às experiências passadas, o que reforça a idéia de que esse serviço, por ser diferenciado, se destaca. No entanto, ao mesmo tempo em que existe a inovação e a defesa dessa proposta, há uma deficiência em constituir alternativas consistentes para transformar os problemas que aparecem no cotidiano. Por esse motivo, poderíamos dizer que o discurso está mais marcado por um protótipo de lamentação do que pela inovação anteriormente comentada.

Vejamos agora uma análise das estruturas que possibilitaram identificar esse padrão discursivo e que fazem parte do contexto discursivo. Começaremos discutindo a percepção geral sobre o funcionamento do serviço, para posteriormente fechar a análise com 
a percepção sobre a formação da equipe do serviço substitutivo.

\section{O funcionamento do serviço}

Analisando inicialmente o discurso, ao ser questionado sobre o funcionamento do serviço e sobre alguns fatores que podem contribuir para melhorá-lo, o entrevistado refere-se à proposta inovadora do mesmo, conforme exposto abaixo:

Eu acho que a proposta do CAD assim, acho ótima, né? Favorece, né? Ah, até pra [cidade do estudo], né? Era necessário que a gente tivesse um Centro de Atenção Psicossocial até porque antigamente quando existia só o ambulatório, se via assim aquelas filas até enormes, das pessoas que queriam consultar com a psicologia e qualquer outro tipo de atendimento na linha terapêutica, né? E eu trabalho desde 95, né? então com a saúde mental, e quando eu entrei, eu já entrei na saúde mental. Então nós trabalhávamos no, a gente chamava de CAPS, né? Mas ainda era um CAPS ambulatorial. Né então, com agendamento, com triagem marcada, com horário pra... todos os funcionários tinham agendamentos. Todos trabalhavam com agenda, né? Então a gente via assim, apareciam muitas dificuldades, e... a gente começou a pensar uma forma de melhorar, aí surgiu assim o CAPS." (Trabalhador).

À primeira vista, algumas estruturas linguísticas denominadas "intensificadores discursivos" são encontradas no discurso. Essas estruturas fazem parte dos processos de modalização da linguagem, ou seja, procuram ressaltar ou reafirmar juízos de valor sobre um determinado assunto, de modo a enfatizar um significado dentro de uma escala de graduação, que vai do maior ao menor ${ }^{(15)}$.

Quando a entrevistada se refere à proposta como sendo "ótima", o uso desse adjetivo funciona como uma atitude valorativa, de enfatizar o quanto a proposta inovadora do CAPS é superior e bem aceita em relação à proposta mais tradicional. Em uma escala de graduação, algo "ótimo" é melhor do que "bom", e isso intensifica a demanda do sujeito, o qual defende os êxitos do funcionamento substitutivo do manicômio, potencializando suas funções, suas finalidades, a sua qualidade assistencial e as mudanças que são trazidas por ele.

Para fortalecer a idéia de que a proposta atual é ótima, o entrevistado se utiliza de uma estratégia narrativa, que compara, detalhadamente, as diferenças e as verossimilhanças entre o que foi feito no passado e o que está sendo feito hoje. Nessa modalidade, a informante se posiciona como sujeito ativo do processo, como sujeito que trabalhou no processo de mudanças que originaram o serviço substitutivo de saúde mental. Ao contrário de um posicionamento mais particularizado, a entrevistada reforça a equipe como a protagonista dessas transformações, pois seguidamente desloca a sequência discursiva do singular (o "eu") para o coletivo plural (o "a gente"). Isso dá ao entender que o sujeito se considera ativo nesse processo de transformação, mas que ela só ocorreu com a mobilização de um coletivo representado numa equipe de trabalhadores, com objetivos bem definidos.

O discurso da entrevistada deixa claro o interesse em defender a proposta atual do serviço não somente pelo uso do adjetivo intensificador. Dentro da estrutura do discurso, o entrevistado também utiliza alguns recursos argumentativos, tendo por base uma visão condicional dos dois modos de operar no interior do serviço. Isso quer dizer que se a proposta atual "favorece" e "era necessária", é porque a anterior "não favorecia" e "gerava problemas". No contexto investigado, é dizer que a proposta atual, comunitária, é a mais adequada para a realidade do município, enquanto que a anterior (a ambulatorial) não era suficiente e agregava uma série de dificuldades.

No contexto da saúde mental, os serviços substitutivos nascem como possibilidades concretas de reorientar a lógica do modelo manicomial, que encarcerava o sujeito dentro de espaços limitados de atendimento para dar centralidade ao tratamento da doença. No contexto da Reforma Psiquiátrica, procura-se dar vazão aos espaços de produção de novos sentidos para a loucura, como fenômeno da vida e que pode (e deve) ser incluído na sociedade, no intuito de valorizar as trocas, os contextos, os sujeitos, a autonomia e a libertação dos indivíduos ${ }^{(16)}$.

No caso do modelo ambulatorial, a entrevistada refere-se aos agendamentos frequentes e às "filas enormes". Qualquer fila já é desagradável por natureza; mas num serviço de saúde, que pretende se tornar acessível, acolhedor e disponível à comunidade, as filas são responsáveis pela paralisação e pela subversão de usuários e trabalhadores ao constante regramento, muitas vezes inflexível. Isso quer dizer que, no ambulatório, não eram os profissionais os controladores de seu processo de trabalho, mas as filas. Os profissionais não eram os protagonistas da ação, mas reféns do contexto.

Outro ponto que merece destaque é a transformação de um ambulatório em um serviço de atenção psicossocial. É uma ampliação importante para o contexto em que vivia Joinville e possível do ponto de vista técnico-político. A oração chave para essa discussão é a de que "a gente chamava de CAPS, né? Mas era um CAPS ambulatorial". Nesse caso, é possível analisar o contexto de inserção tanto do ponto de vista do CAPS, quanto do ponto de vista do ambulatório. A referência que possibilita essa análise é o uso do conector contra-argumentativo 
"mas".

Na primeira situação, compreendemos que a entrevistada refere que o serviço era um ambulatório para a equipe, mas chamado pelos profissionais de CAPS. Essa ampliação sobre o conceito do serviço já poderia ser considerada como uma inovação, pois há certo rompimento com um paradigma que orienta uma prática centrada na rotinização, na cristalização do conhecimento e na dissolução das relações horizontais entre as pessoas. Portanto, a ampliação vai desde o conceito do próprio serviço (o que é), até o objetivo principal de seu funcionamento (para que serve) e a organização interna do processo de trabalho dos profissionais (como se faz). Um processo que não é simples, pois, para produzir transformações qualitativas na instituição, é necessário ter tempo, mobilização coletiva e interesse para processar as mudanças.

No entanto, ao analisar o serviço do ponto de vista do CAPS, mas que funciona como ambulatório, o significado intencional da sequência discursiva parece inverter-se. O serviço passaria a ser entendido como um serviço diferenciado, que procura produzir novas relações com a sociedade, mas que ainda apresenta resquícios de um modelo mais tradicional de atendimento. "Ainda", porque a equipe (novamente a valorização do coletivo em detrimento de um indivíduo específico) "começou a pensar uma forma de melhorar" ou porque "íamos discutindo", expressões estas que procuram passar a idéia de um processo coletivo inacabado, em andamento, em continuidade, como se a equipe estivesse buscando, cotidianamente, as respostas para superar suas dificuldades conceituais e operacionais.

Existe uma dificuldade lógica da psiquiatria para desamarrar-se de saberes baseados na racionalização da vida como retórica da verdade absoluta. Ela desenvolveu-se como ciência a partir da seqüestração dos corpos, para explorá-los, observálos e classificá-los. Uma loucura, transmitida para a sociedade como um vício da razão delirante, como produto da periculosidade, da marginalidade social e das respostas anormais dos processos adaptativos do homem à sociedade. Por isso, parece compreensível o fato de os trabalhadores apresentarem dificuldades na sistematização de novos conhecimentos. Isso porque a loucura ainda repousa no imaginário social como um produto do desconhecido, a ser afastado e tratado em instituições especializadas ${ }^{(17)}$.

Nesse sentido, entendemos que o novo saber da psiquiatria que se amplia para o círculo social e tem caráter reformista, tem incentivado o redimensionamento de saberes e práticas, além de trazer consigo algumas contradições. Nesse caso, o ambulatório - que já representa a superação de modalidades de atendimento baseadas no confinamento da loucura - também parece ser tensionado pelos sujeitos ao longo do processo como um serviço tipicamente centralizador, organizado em disciplinas e pouco focalizado nas demandas totalizadoras da vida dos sujeitos. A necessidade de ampliação (ou desconstrução) do ambulatório para dar vazão ao nascimento de um novo serviço, desta vez comprometida com a comunidade e com funcionamento interdisciplinar, parece ser um desafio não somente estrutural, mas também um processo de desconstrução interna. Isso porque mobiliza os sujeitos a repensarem novas estratégias e caminhos para lidar com a loucura no micro-espaço onde ocorre o cuidado.

A seguir, passaremos a discutir essas e outras questões relacionadas à formação da equipe de saúde mental.

\section{A formação da equipe de saúde mental}

Pensamos que, no contexto da Reforma Psiquiátrica, a mutabilidade das práticas parece ser um desafio candente às relações entre as diferentes disciplinas no campo da saúde mental. De certa forma, esse contexto exige uma transformação substantiva no modo de operar dos serviços comunitários, ao mesmo tempo em que surgem resistências naturais, ambas manifestadas no discurso. A começar pela própria constituição da equipe de saúde mental que, por mais que esteja comprometida com o funcionamento interdisciplinar, ainda parece priorizar as habilidades e competências propostas pela multidisciplinaridade do atendimento: Quando nós trabalhava no antigo CAPS, era Saúde mental toda centralizada dentro de um único ambulatório, então eram todos os funcionários, todos os psiquiatras, todos os psicólogos, todos assistentes sociais... Aí começamos a pensar nesse CAPS, com essa proposta nova, daí onde então se aumentou o número de equipe e colocou-se psicólogos e mais terapeutas ocupacionais. (Trabalhador).

Quando se reportava ao contexto ambulatorial, o entrevistado relatava que a saúde mental era toda centralizada no ambulatório. E essa saúde mental era especificamente "todos os funcionários, todos os psiquiatras, todos os psicólogos, todos assistentes sociais...". Em primeiro lugar, no que se refere ao elemento "todos os funcionários", parece haver uma tentativa de homogeneizar as categorias. Mais do que isso, o profissional está buscando um conceito de equipe como unidade, como um coletivo singularizado em um espaço de tratamento específico, onde a atuação em conjunto é fundamental para trabalhar com as diferentes dimensões da loucura. Essa postura também vai ao encontro do que acreditamos hoje ser uma equipe interdisciplinar, onde se mantêm e respeitam-se as especificidades, mas onde se valoriza principalmente o equilíbrio entre um saber específico - próprio de cada categoria - e a atuação em forma de 


\section{compartilhamento.}

A mudança no campo da saúde mental, com a atenção psicossocial, apresenta a interdisciplinaridade como uma solução para os problemas da psiquiatria tradicional, que isola e compartimentaliza o saber, fundamentando-se na horizontalização das relações e dos conhecimentos para promover vida. Interdisciplinaridade é articular os conhecimentos específicos com o de toda uma rede de saberes envolvidos no sistema de saúde, sempre tendo em vista a necessidade da ação dialógica entre os atores sociais ${ }^{(18-19)}$.

A interdisciplinaridade reforça a tendência de superação do compartilhamento do saber, como um dispositivo que busca, no seio da Reforma Psiquiátrica, integrar habilidades e competências que possam compreender a loucura como fenômeno da complexidade. Entendemos que essa união de esforços pode ajudar na transformação, no rompimento com padrões cristalizados de atendimento e no combate aos vícios de um modelo tradicional que ainda reside em nosso meio. Dessa forma, é possível promover a ressignificação de saberes, de práticas, de instituições e, principalmente, de pessoas.

Aos poucos, aquele coletivo formado por "todos os funcionários" parece ser dissolvido para formar "micro-equipes". Existe agora "micro-equipes", compostas por todos os "psiquiatras", todos os "psicólogos" e todos os "assistentes sociais".

Por mais que pretenda reunir todos os sujeitos para formar um coletivo singularizado, a diluição do saber interdisciplinar e sua concentração nos aspectos multidisciplinares parecem reforçar a tendência ainda hierarquizada com que ocorre a constituição da equipe de saúde mental. Nesse caso, a hierarquização fica a cargo do tipo de competência técnica dos profissionais de nível superior, quando inicia no psiquiatra e termina no assistente social. Se no discurso a equipe aparece organizada inicialmente a partir do psiquiatra para depois terminar nas outras categorias, logo o processo de trabalho da equipe também parece ser organizado em torno da psiquiatria. Desse modo, é possível comprovar como o ambulatório estava organizado para atender a demanda de saúde mental na cidade estudada, numa lógica hegemônica tradicional, que via, na disciplina psiquiátrica, uma razão instrumental para compreender os fenômenos psíquicos.

No estudo de Lougon $^{(20)}$ sobre os vários conceitos e dispositivos desenvolvidos pela psiquiatria brasileira na história e na atualidade, os trabalhadores parecem realizar, em seus discursos, uma distinção precisa sobre a função do "técnico" e do "funcionário" dos serviços de saúde mental de perspectiva comunitária. Segundo o autor, os profissionais costumam chamar de "técnico" aquele que possui nível superior ou para designarem-se a si próprios no cotidiano de sua prática. No caso dos "funcionários", geralmente prevalece, para efeitos de classificação, o nível de contrato e a formação, que, ao invés de ressaltarem a integração, aumentam a distância entre as duas categorias. Assim, o médico, o psicólogo ou a assistente social formariam uma única categoria profissional ("técnico"), responsável pelo trabalho abstrato, homogênea; o grupo "funcionários", no entanto, seria formado pelos profissionais de nível fundamental e médio, responsáveis pelo trabalho mais elementar, como no caso dos cuidados diretos aos indivíduos.

Vale lembrar que essa organização multidisciplinar parece aceitável no momento em que a saúde mental do município estava reduzida a um único espaço de atendimento (o ambulatório). De certa forma, entendemos que o ambulatório de saúde mental, por possuir uma base comunitária, já representa a superação estrutural de modalidades de atendimento centradas no ambiente hospitalar psiquiátrico. No espaço das relações, no entanto, se a saúde mental era "o ambulatório", a saúde mental também estaria concentrada nas "disciplinas" que trabalhavam nesse serviço, e não nos sujeitos que as representam. No modelo ambulatorial, desloca-se o coletivo singularizado de trabalhadores para dar espaço a um conjunto de especificidades tecnológicas (habilidades e competências) fragmentadas, que pouco valorizam o significado comum do próprio trabalho em conjunto.

Dando continuidade ao processo de constituição da equipe, no período de transição, quando o serviço passa a incorporar as prerrogativas de funcionamento de um CAPS, a solução encontrada pelos trabalhadores era a de acrescentar novos profissionais para tentar diversificar o trabalho concentrado naquele modelo tradicional de atendimento. Para isso, a composição da equipe foi modificada com a inserção de psicólogos e terapeutas ocupacionais, que não faziam parte anteriormente da equipe do ambulatório, mas que era requisito básico para que o antigo serviço passasse a funcionar e fosse credenciado como CAPS.

Conforme a Portaria 336/2002 do Ministério da Saúde, um CAPS II (o caso do município estudado) deve possuir capacidade operacional para atender municípios com população entre 70.000 e 200.000 habitantes. A equipe técnica deve ser composta por 12 (doze) profissionais de diferentes áreas, sendo obrigatória a presença de um médico e de um enfermeiro. Entre os profissionais de nível superior, destacam-se psicólogos, terapeutas ocupacionais, assistentes sociais, pedagogos ou outra categoria profissional necessária para o cumprimento do projeto terapêutico, definido pelos próprios trabalhadores em conjunto com a gestão municipal.

Sabemos que a exigência normativa não totaliza o conhecimento local das práticas no interior de cada 
serviço, por se tratar de um instrumento regulatório que apenas orienta o modo estrutural de funcionamento do mesmo. Nesse caso, fica a equipe responsável por administrar o cotidiano das práticas, assim como responsável pelo cuidado no seu território. Ainda que exista uma tendência da equipe em focalizar-se nas normativas para promover o cuidado, a própria normativa é capaz de evitar a inércia ao pluralizar o conhecimento (e as habilidades profissionais) sobre algo impossível de ser concentrado em determinadas especificidades técnicas (a loucura). Isso resgata o papel da interdisciplinaridade como proposta fomentadora de novos sujeitos, de novas ideologias e de novos saberes no contexto social da Reforma Psiquiátrica.

\section{CONSI DERAÇÕES FI NAIS}

O presente estudo procurou analisar o discurso de um trabalhador de um serviço substitutivo de saúde mental acerca de aspectos relacionados à constituição da equipe de trabalho no contexto da Reforma Psiquiátrica. Para tanto, utilizamos, como abordagem teórico-metodológica, a análise crítica de discurso.

Ficou evidente que o discurso do trabalhador procura resgatar questões válidas e importantes para repensar a prática e os saberes no campo psicossocial, transitadas entre a constituição da equipe de saúde mental e o modo de funcionamento do serviço. Entendemos que a loucura, como um fenômeno complexo da vida, necessita desse olhar ampliado, que possa contemplar as diferentes dimensões de sua existência e de sua subjetividade. Para isso, as equipes de saúde mental devem organizar-se em torno de uma lógica interdisciplinar, que sustente uma relação horizontal e comprometida com as diferentes demandas que o sujeito apresenta.

No decorrer da análise do material discursivo, parece haver uma tendência do trabalhador em ressaltar a relevância do modelo psicossocial, centrado no desenvolvimento de práticas e esforços que atendam aos anseios e às necessidades da loucura e do louco em toda sua complexidade biopsicossocial. Também é possível perceber a existência de resquícios de práticas e saberes compatíveis com modelos mais tradicionais de atendimento em saúde mental, concentrados em dinâmicas de processo de trabalho polarizadas em determinadas disciplinas e pouco numa tendência integradora e de cooperação entre elas. I sso, sob nosso ponto de vista, é fruto da própria transição entre modelos distintos, o que não representa um retrocesso, ao contrário, uma excelente oportunidade para a constante produção/transformação das relações entre essas disciplinas e das trocas existentes entre elas.

Esperamos que este estudo sirva de subsídio para outros estudos na área, para compreender como, discursivamente, nossa sociedade se relaciona, absorve, critica, apóia ou se distancia da loucura, do louco e de suas relações.

\section{REFERÊNCIAS}

1. Martins A. Novos paradigmas e saúde. Physis. 1999; 9(1): 83-112.

2. Foucault M. O nascimento da clínica. 6th ed. Rio de J aneiro: Forense Universitária; 2004.

3. Castel R. A ordem psiquiátrica: a idade de ouro do alienismo. 1st ed. Rio de Janeiro: Graal; 1978.

4. Pessotti I. A loucura e as épocas. 1th ed. Rio de J aneiro: 34; 1994.

5. Kantorski LP. Mental health care in Brazil. J Psychiatr Ment Health Nurs. 2002; 9:251-3.

6. Hirdes A. A Reforma Psiquiátrica no Brasil: uma (re) visão. Cien Saude Colet. 2009; 14(1):297-305.

7. Fleury S. A Reforma Sanitária e o SUS: questões de sustentabilidade. Cien Saude Colet. 2007; 12(2): 307-17.

8. Koda MY. Da negação do manicômio à construção de um modelo substitutivo em saúde mental: o discurso de usuários e trabalhadores de um núcleo de atenção psicossocial [dissertation]. São Paulo: Instituto de Psicologia/USP; 2002. 186p.

9. Antunes SMMO, Queiroz MS. A configuração da Reforma Psiquiátrica em contexto local no Brasil: uma análise qualitativa. Cad Saude Publica. 2007;23(1):207-15.

10. Wodak R. What CDA is about - a summary of its history, important concepts and it's developments. In: Wodak R, Meyer M. Methods of critical discourse analysis. 5th ed. London: SAGE Publications; 2001. p. 1-14.

11. Van Dijk T. Discourse, context and cognition. Discourse studies. 2006; 8(1): 159-77.

12. Chouliaraki L, Fairclough N. Discourse in late modernity: rethinking critical discourse analysis. 5th ed. Edinburg: Edinburgh University Press; 2005.

13. Pinho LB, Kantorski LP, Bañon Hernández AM. Critical discourse analysis - new possibilities for scientific research in the mental health area. Rev Lat Am Enfermagem. 2009; 17(1): 126-32.

14. Llisteri J. La representación ortográfica de corpus orales [Internet]. Barcelona: Universitat Autònoma de Barcelona; 2008 Oct 26 [cited 2010 mar 31]. Available

from:

http://liceu.uab.es/ joaquim/language resources/sp oken_res/Repres_ortog_corp_oral.html.

15. Calsamiglia-Blancafort $H$, Tusón-Valls $A$. Las cosas del decir - manual de análisis del discurso. 2nd ed. Barcelona: Ariel; 2007.

16. Amarante P. A clínica e a Reforma Psiquiátrica. 1sd ed. Rio de Janeiro (Brasil): Capítulo 2; p. 45-65. 17. Basaglia F. A instituição negada. 3rd ed. Rio de J aneiro: Graal; 2001.

18. Tavares CMM. A interdisciplinaridade como requisito para a formação da enfermeira psiquiátrica 
na perspectiva da atenção psicossocial. Texto Contexto Enferm. 2005; 14(3): 403-10.

19. Filizola CLA, Milioni DB, Pavarini SCl. A vivência de trabalhadores de um CAPS diante da nova organização do trabalho em equipe. Rev. Eletr. Enf. [Internet]. 2008 [cited 2009 mar 31]; 10(2): 491-503. Avaiable

from:

http://www.fen.ufg.br/revista/v10/n2/v10n2a20.htm

20. Lougon M. Psiquiatria institucional: do hospício à Reforma Psiquiátrica. 1st ed. Rio de Janeiro: Fiocruz; 2006.

Artigo recebido em 20.03.09.

Aprovado para publicação em 15.03.10.

Artigo publicado em 31.03.10. 